\title{
Spatiotemporal Dynamics of Maximum Wind Speed Using the Wind Multiplier Downscaling Method in the Yangtze River Inland Waterway from 1980 to 2017
}

\author{
Lijun Liu ${ }^{1}$ and Fan Zhang ${ }^{1,2, *}$ \\ 1 School of Navigation, Wuhan University of Technology, Wuhan 430063, China; liulijun@whut.edu.cn \\ 2 Hubei Key Laboratory of Inland Shipping Technology, Wuhan 430063, China \\ * Correspondence: michael_zf@whut.edu.cn; Tel.: +86-10-13871433443
}

check for

updates

Citation: Liu, L.; Zhang, F. Spatiotemporal Dynamics of Maximum Wind Speed Using the Wind Multiplier Downscaling Method in the Yangtze River Inland Waterway from 1980 to 2017. Atmosphere 2021, 12, 1216. https:// doi.org/10.3390/atmos12091216

Academic Editors: Tinghai Ou, Xuejia Wang and Hengde Zhang

Received: 19 August 2021

Accepted: 15 September 2021

Published: 17 September 2021

Publisher's Note: MDPI stays neutral with regard to jurisdictional claims in published maps and institutional affiliations.

Copyright: (c) 2021 by the authors. Licensee MDPI, Basel, Switzerland. This article is an open access article distributed under the terms and conditions of the Creative Commons Attribution (CC BY) license (https:// creativecommons.org/licenses/by/ $4.0 /)$.

\begin{abstract}
Wind speed affects the navigational safety of the Yangtze River, and assessing its spatiotemporal dynamics provides support for navigation management and disaster prevention. We developed a wind multiplier downscaling method integrating the effects of land use and topography, and used meteorological station observations and European Center for Medium-Range Weather Forecasts (ECMWF) Reanalysis Interim (ERA-Interim) reanalysis data for statistical downscaling in the Yangtze River inland waterway region from 1980 to 2017. Compared with reanalysis data, the downscaling products showed improved accuracy (especially at 5-10 m/s), and are consistent with site-based interannual variability observations. Increasing maximum wind speeds in the middle-downstream area was observed from 1980 to 1990, while a decreasing trend was observed from 2010 to 2017; the opposite was observed for the upstream. Land use has significant influence on wind speed, with a decreasing trend observed year by year for wind speed above grade 9. Although the proportion of grade 4-8 wind speed over water is small and the trend is not obvious, grade 9-10 wind speeds displayed an increasing trend from 2010 to 2017, indicating that changes in surface roughness have a significant influence on wind speed in the Yangtze River inland waterway.
\end{abstract}

Keywords: maximum wind speed; reanalysis data; wind multiplier; statistical downscaling; topography; surface roughness

\section{Introduction}

Large-scale human activities have led to drastic changes in the frequency of strong winds over the land surface, considerably endangering the safety of inland navigation and sustainable regional socio-economic development [1,2]. The cargo throughput of Yangtze River inland waterway transport accounts for approximately $55 \%$ of total cargo transport in China. Strong winds and associated secondary disasters (e.g., power disruption, bridge damage, ship accidents, etc.) have become the main destructive weather- and climaterelated events along the Yangtze River inland waterway transportation [3]. For example, in June 2015, a tornado caused the sinking of the "Eastern Star" passenger ship [4]. The traditional view is that wind speeds in the Yangtze River basin have generally been decreasing over the past 50 years [5], which may be related to the rising Arctic Oscillation (AO) index, urbanization, and large-scale climate change $[6,7]$. However, a new study found a rebounding trend in global surface wind speeds from 2010 to 2017, with a $17 \pm 2 \%$ increase in potential wind energy [8]. Climate change has significantly affected the frequency, intensity, and magnitude of variability in global wind speeds [9]. Land use/land cover changes (e.g., urbanization) can affect the surface roughness and cause small-scale wind disturbances [10]; spatiotemporal variation in wind speed at large scales is further influenced by wind speed perturbations [11]. Although the spatiotemporal variation relationships of wind speed at regional-global scales are well understood, characterizing multi-scale 
maximum wind speed variation due to urbanization and other surface processes in the Yangtze River inland waterway remains problematic.

Wind speed data for inland waterways are mainly derived from river-shore meteorological stations, $80-100 \mathrm{~m}$ meteorological observation towers, and climate data; the meteorological observations are often limited to monitoring environments, with missing data and low estimation [12]. European Center for Medium-Range Weather Forecast (ECWMF) reanalysis data can be used to characterize long time series and large-scale climate changes caused by atmospheric circulation and greenhouse gas emissions, which are also a source of data for analyzing the spatiotemporal characteristics of wind speeds at regional scales [13]. However, ECWMF reanalysis data do not sufficiently consider land surface processes during assimilation, resulting in low estimates of wind speed and low sensitivity to land use change [14].

To address these issues, scale-down methods are generally used to downscale coarsegrid reanalysis data to local values. For example, statistical downscaling methods have been used to extrapolate and interpolate riverbank observations to obtain river surface wind speeds [15], dynamic downscaling methods such as numerical simulations of weather forecasts have been adopted to obtain accurate data [16], and coupled dynamic-statistical downscaling methods (e.g., the Wind Atlas Analysis and Application program) can also be used $[17,18]$. These methods can effectively reduce prediction-observation errors due to missing local features in climate models [19]. Specifically, dynamic downscaling methods are numerical weather prediction models get their initial and boundary conditions from a low-resolution global forecast system and are interpolated into the model domain of interest [20], which are sensitive to the boundary conditions, often lack assimilation in the initialization of mesoscale models, require a large computational volume, and have the uncertainty of interpolation methods and large systematic spatial errors. [21,22]; traditional statistical methods are based on modeling meteorological observation factors and do not consider the influence of geographical elements such as land use and topographic environment on wind speed; coupled dynamic-statistical downscaling methods are limited by the computational capacity of computational fluid dynamics models and cannot provide large-scale and long time series products. Among them, improved statistical downscaling methods can be used to consider the effects of surface processes and effectively reduce reanalysis data errors [23], with good reliability and applicability [24], such as the wind multiplier method that integrates the effects of land use and topography $[25,26]$. Therefore, this method can be developed for complex geographical environments; in the case of this study, we used it to provide a high-precision wind speed dataset for the Yangtze River inland waterway.

To highlight the above key scientific issues and knowledge gaps, a regional wind multiplier downscaling method integrating high-precision land cover and topographic local effects was proposed. Using this method, reanalysis wind speed data for 1980, 1990, 2000, 2010, and 2017 at $0.7^{\circ} \times 0.7^{\circ}$ resolution was downscaled from a coarse grid to high spatial resolution data ( $1 \mathrm{~km} \times 1 \mathrm{~km}: 1980-2010 ; 10 \mathrm{~m} \times 10 \mathrm{~m}: 2017)$, and the spatiotemporal characteristics of the downscaled maximum wind speed we determined. We focused on assessing wind speed heterogeneity in the water-land area. The results provide scientific reference and data support for navigation management and disaster prevention and mitigation in the Yangtze River inland waterway. Specifically, (1) the land use and elevation datasets were integrated to obtain the surface roughness parameter $M_{z}$ and the slope parameter $\mathrm{M}_{\mathrm{h}}$, respectively, and the wind multiplier downscaling method was used to obtain a high-resolution wind speed dataset, which is applicable to the navigable environment of the Yangtze River inland waterway; (2) the observed and downscaled wind speed data were compared and analyzed using spatial mapping methods, and the accuracy of downscaled products was assessed using three error test metrics (the Kolmogorov-Smirnov two-sample test, mean difference, and $R^{2}$ ) based on comparison to 51 meteorological stations in the study area; (3) the spatiotemporal characteristics of the downscaled maximum wind speed 
data under different land use types were analyzed, and the applicability and potential improvement of the wind multiplier downscaling method was considered.

\section{Data and Methods}

\subsection{Data}

Based on the segment management regulations of Changjiang Waterway Bureau (http:/ / www.cjhdj.com.cn/, accessed on 13 September 2021), the Yangtze River inland waterway $\left(104^{\circ} 28^{\prime} 1^{\prime \prime} \mathrm{E}-121^{\circ} 54^{\prime} 10^{\prime \prime} \mathrm{E}, 27^{\circ} 39^{\prime} 30^{\prime \prime} \mathrm{N}-32^{\circ} 42^{\prime} 28^{\prime \prime} \mathrm{N}\right)$ was divided into 9 sections (Figure 1): Shanghai section, Nanjing section, Anhui section, Jiujiang section, Yueyang section, Wuhan section, Yichang section, Chongqing section, and Yibin section. In accordance with the characteristics of waterway maintenance, management, and research practices [27], the inland waterways of the Yangtze River were further grouped into three major waterway areas using ArcGIS 10.5 software (esri, Redlands, CA, USA): the upstream waterway from the Yibin section to the Chongqing section, the midstream waterway from the Yichang section to the Jiujiang section, and the downstream waterway from the Anqing section to the Shanghai section.

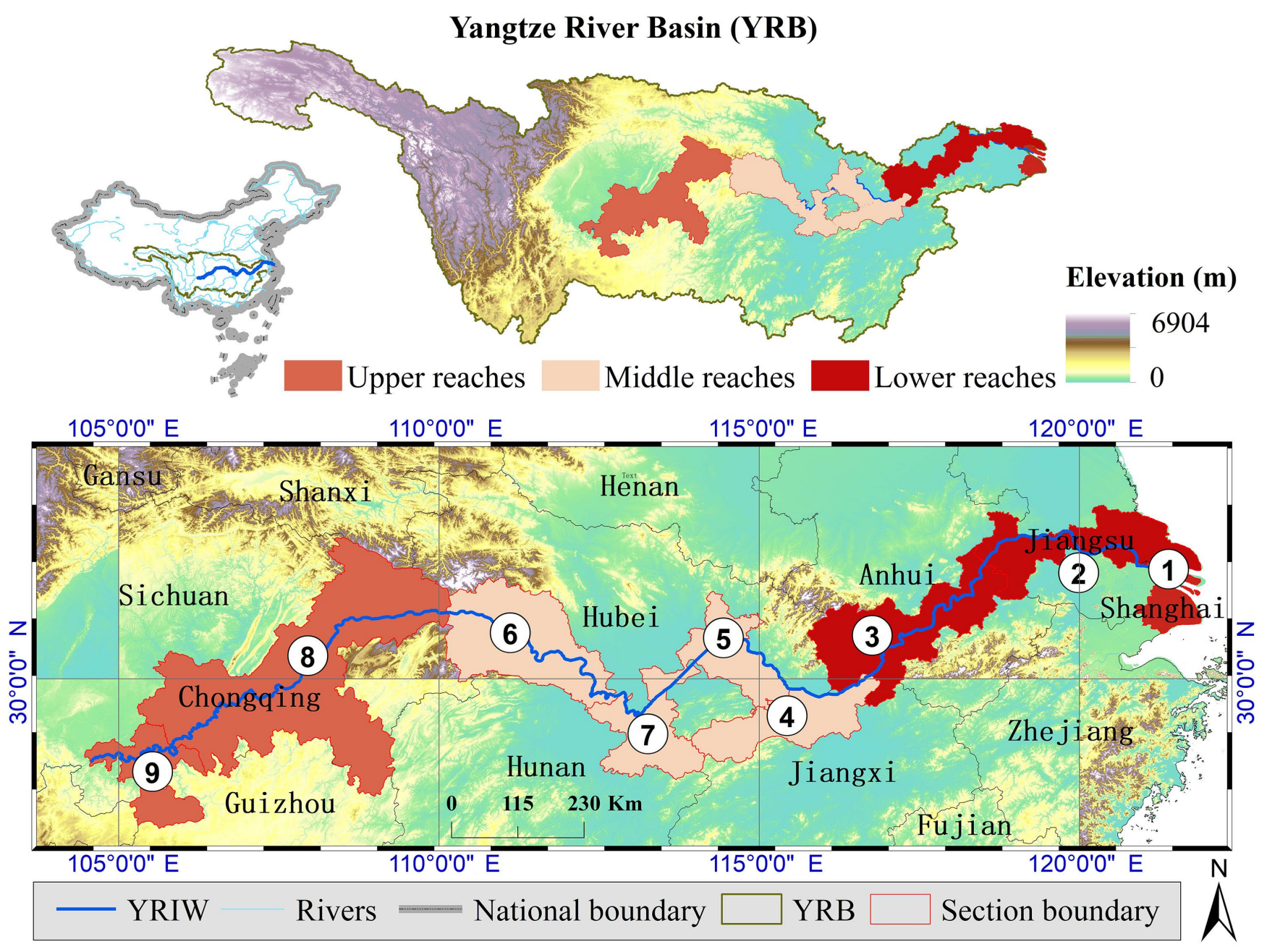

Figure 1. Map of the study area (1) Shanghai section, (2) Nanjing section, (3) Anhui section, (4) Jiujiang section, (5) Yueyang section, (6) Wuhan section, (7) Yichang section, (8) Chongqing section, and (9) Yibin section).

Meteorological observations were obtained from the Global Surface Summary of the Day (GSOD) dataset (https: / / www.ncei.noaa.gov/access/search/data-search/globalsummary-of-the-day, accessed on 13 September 2021) for 1980-2017. The dataset was subjected to multi-process automated data quality control to eliminate random errors and 
mistakes [28]. First, we obtained 51 available stations from 101 ground-based meteorological stations in the study area to satisfy the time continuity and data integrity of strong wind analysis, and then extracted the $10 \mathrm{~m}$ daily maximum wind speed $\left(V_{\max \_ \text {OBS }}\right)$ to validate the accuracy of the maximum wind speed downscaling product. Second, we extracted 14 representative riverine stations near the river surface from the 51 stations (Table 1) to analyze the maximum wind speed trend within the navigation segment. The reanalysis information was obtained from the ECMWF Reanalysis Interim (ERA-Interim) dataset (https:/ /apps.ecmwf.int/datasets/, accessed on 13 September 2021). The ERA-Interim product is a uniform Gaussian grid surface grid point field (horizontal latitude and longitude grid $0.7^{\circ} \times 0.7^{\circ}$ ); it is operated by the ECMWF Integrated Forecasting System cycle $31 \mathrm{r} 2$ and integrates a variety of physical processes of sea-air-land interactions. The product is credible and can effectively describe the spatiotemporal dynamics of the atmosphere, wind, and waves that affect navigation [29]. Specifically, the $10 \mathrm{~m}$ maximum wind speed $\left(V_{\text {max_ERA }}\right)$ of the ERA-Interim dataset was extracted using the Python 3.8 software.

Table 1. Location information for 14 stations in the study area.

\begin{tabular}{|c|c|c|c|c|c|c|}
\hline Stream & Section & No. & Name & Latitude $\left(^{\circ}\right)$ & Longitude $\left({ }^{\circ}\right)$ & Elevation (m) \\
\hline \multirow{4}{*}{ Upstream } & Yibin & 56492 & Yibin & 28.8 & 104.6 & 342 \\
\hline & \multirow{3}{*}{ Chongqing } & 57426 & Liangping & 30.683333 & 107.8 & 455 \\
\hline & & 57633 & Youyang & 28.833333 & 108.766667 & 665 \\
\hline & & 57348 & Fengije & 31.016667 & 109.533333 & 303 \\
\hline \multirow{6}{*}{ Midstream } & \multirow{2}{*}{ Yichang } & 57461 & Yichang & 30.733333 & 111.366667 & 257.7 \\
\hline & & 57476 & Jingzhou & 30.333333 & 112.183333 & 33 \\
\hline & Yueyang & 57584 & Yueyang & 29.383333 & 113.083333 & 52 \\
\hline & Wuhan & 57494 & Wuhan & 30.783758 & 114.2081 & 34.44 \\
\hline & \multirow{2}{*}{ Jiujiang } & 57598 & Xiushui & 29.033333 & 114.583333 & 147 \\
\hline & & 58506 & Lushan & 29.583333 & 115.983333 & 1165 \\
\hline \multirow{4}{*}{ Downstream } & Anqing & 58424 & Anqing & 30.616667 & 116.966667 & 63.2 \\
\hline & Nanjing & 58238 & Nanjing & 31.742042 & 118.862025 & 14.93 \\
\hline & \multirow{2}{*}{ Shanghai } & 58367 & Longhua & 31.197875 & 121.336319 & 3.04 \\
\hline & & 58265 & Lvsi & 32.066667 & 121.6 & 9.6 \\
\hline
\end{tabular}

The geographic data primarily included land use data and a digital elevation model (DEM). The 1980-2015 Landsat dataset in China $(1 \mathrm{~km} \times 1 \mathrm{~km})$ was obtained from the Chinese Academy of Sciences Resource and Environmental Science Data Center (http: / / www.resdc.cn/, accessed on 13 September 2021) [30]; this dataset is based on Landsat's Thematic Mapper (TM) and Enhanced Thematic Mapper (ETM) images, through manual visual interpretation and multiple sources. The land use types include 6 primary types (arable land, forest land, grassland, water, residential land, and unused land) and 25 secondary types. The 2017 land use data were derived from the Finer Resolution Observation and Monitoring of Global Land Cover 10 (FROM-GLC10) dataset (http:/ / data.ess.tsinghua.edu.cn/, accessed on 13 September 2021), which successfully produced the world's first 10-m resolution 10-classification land cover map using a finite sample stable classification method [31]. Land use data for the years 1980, 1990, 2000, and 2010 were reclassified into cropland, forest, grassland, shrubland, wetland, water, tundra, impervious surface, bare land, and snow/ice based on the classification descriptions of the 2017 land use data. The DEM was derived from the Shuttle Radar Topography Mission (SRTM) dataset $(90 \mathrm{~m} \times 90 \mathrm{~m}$, https:/ / cgiarcsi.community / data/srtm-90m-digital-elevation-database-v4-1/, accessed on 13 September 2021) [32] and resampled to the spatial resolution of the corresponding land use data. Then, the land use data and DEM were subjected to standard pre-processing such as projection transformation (Krasovsky_1940_Transverse_Mercator) and clipping [33] to obtain the DEM data of the study area (Figure 1) and a land use dataset from 1980 to 
2017 (Figure 2). Finally, the spatial analysis module of ArcGIS 10.5 was used to obtain the slope and land use types for the input data of the wind multiplier downscaling method.
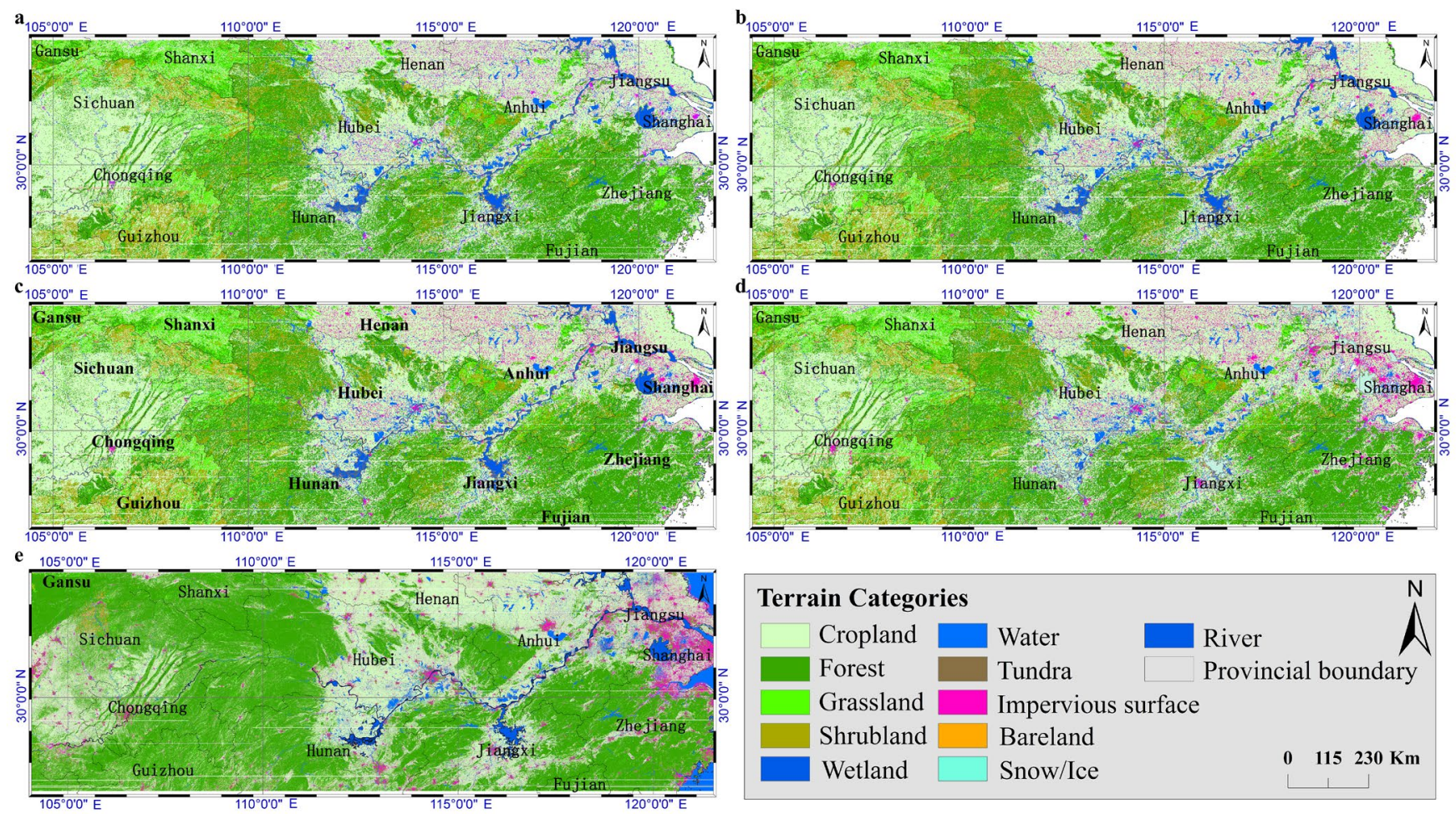

Figure 2. Land use map of the study area from 1980 to 2017. (a) 1980, (b) 1990, (c) 2000, (d) 2010, (e) 2017.

\subsection{Wind Multiplier Method}

The wind multiplier method integrates the effects of land use types and slope on wind speed by using the surface roughness coefficient $\left(M_{z}\right)$ and slope coefficient $\left(\mathrm{M}_{\mathrm{h}}\right)$ to reduce the $10 \mathrm{~m}$ maximum wind speed $\left(V_{\max } E R A\right)$ at the ERA-Interim grid point. Thus, downscaled maximum wind speed $\left(V_{\max \_} W M\right)$ datasets with $1 \mathrm{~km}$ and $10 \mathrm{~m}$ resolutions were obtained for the Yangtze River inland waterway for the period 1980-2017.

$$
\begin{gathered}
V_{\text {max } \_W M}=V_{\text {max } \_E R A} \times M_{z} \times M_{h} \\
\mathrm{TC}=\log _{10}\left(\mathrm{z}_{0} / 2\right)+4
\end{gathered}
$$

where $V_{\text {max } \_ \text {ERA }}$ is the maximum wind speed $(\mathrm{m} / \mathrm{s})$ at the ERA-Interim grid point. $M_{z}$ was calculated by reference to the Australian wind load standard AS/NZS 1170.2 [34] for roughness $\left(\mathrm{z}_{0}\right)$; terrain category (TC) correspond to the original $M_{z}$, which is widely used and has a parametric solution of credibility. A table of the TC, elevation, and $z_{0}$ was first obtained with reference to the above corresponding relationships (Table 2): water and grassland were classified as Class 2 features with heights of $1.5-10 \mathrm{~m}$ and a $\mathrm{z}_{0}$ of $0.02 \mathrm{~m}$; bareland, cropland, wetland, and shrubland were Class 3 features with heights of $0.5-10 \mathrm{~m} . M_{h}$ was used to characterize the effect of topography on wind speed, which is influenced by land steepness and the distance between a site and the nearest topographical high point [35]; there are significant local terrain effects near the tops of the mountains and along the edges of cliffs [36]. New $M_{h}$ values were obtained from the original $M_{h}$-slope corresponding relationship in AS/NZS $1170.2(2011): 1.0\left(<2.9^{\circ}\right), 1.08\left(2.9^{\circ}-5.7^{\circ}\right), 1.16$ $\left(5.7^{\circ}-11.3^{\circ}\right), 1.32\left(11.3^{\circ}-16.7^{\circ}\right), 1.48\left(16.7^{\circ}-24.2^{\circ}\right)$ and $1.71\left(\geqq 24.2^{\circ}\right)$. In summary, distribution maps and parameter sets for $M_{z}$ and $M_{h}$ were obtained for the study area for different periods; for example, good spatial heterogeneity was found in both parameters in 2017 (Figure 3). 
Table 2. Land uses type information for $M_{z}$ in the study area.

\begin{tabular}{ccccccccc}
\hline Land Uses Types & Cropland & Forest & Wetland & Water & Grassland & Shrubland & Impervious & Bareland \\
\hline Nominated height (unit: $\mathrm{m})$ & $3-5$ & $3-10$ & $3-10$ & $1.5-10$ & $1.5-10$ & $0.5-10$ & $3-200$ & $0.5-5$ \\
\hline Terrain category (TC) & 3 & 4 & 3 & 2 & 2 & 3 & 4 & 3 \\
\hline$M_{z}$ & 0.83 & $0.75-1.03$ & 0.83 & $0.91-1.0$ & $0.83-0.92$ & 0.83 & $0.83-1.16$ & 0.83 \\
\hline
\end{tabular}
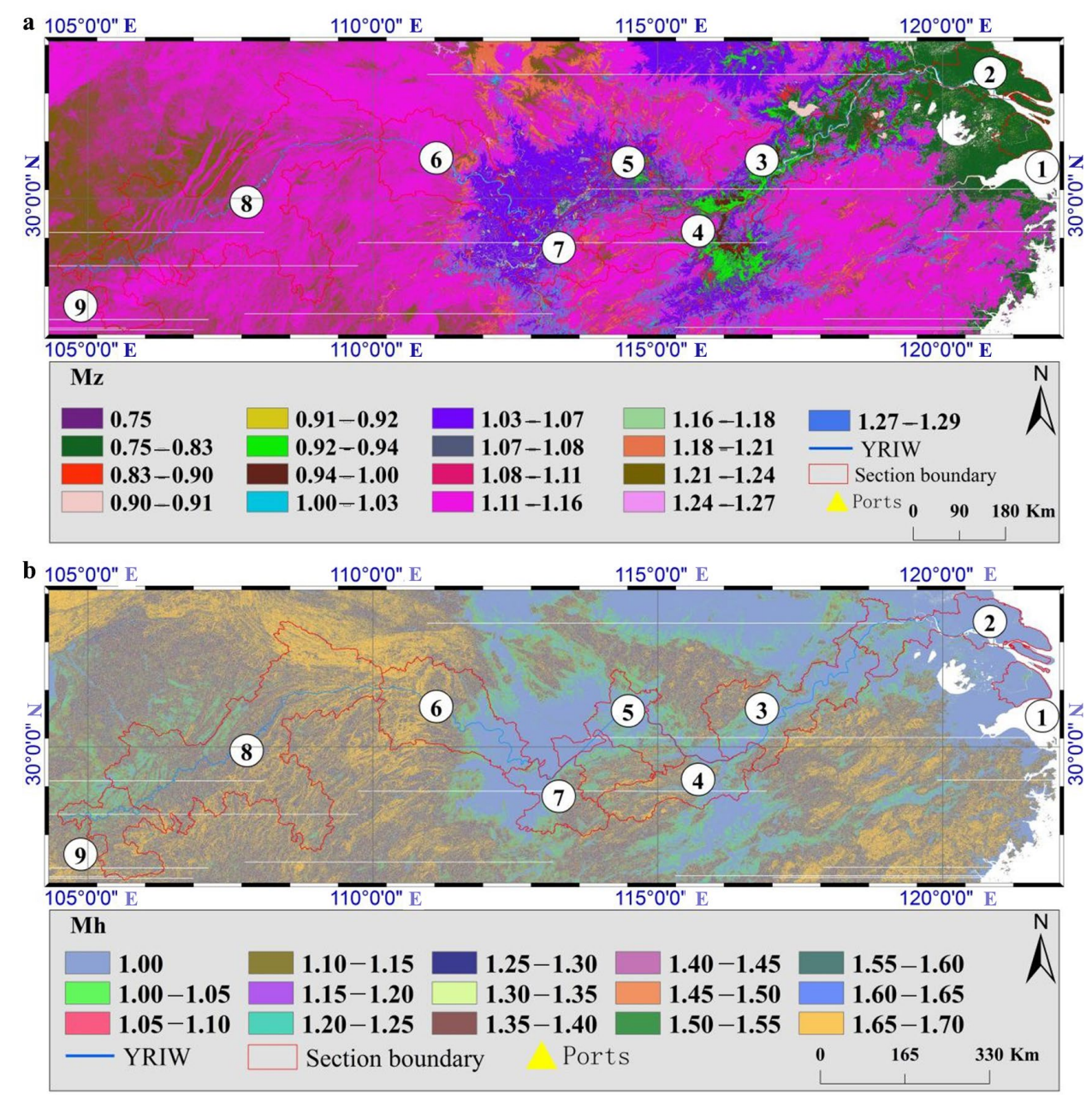

Figure 3. (a) Surface roughness coefficient $\left(M_{z}\right)$ and (b) slope coefficient $\left(M_{h}\right)$ in 2017 (1) Shanghai section, (2) Nanjing section, (3) Anhui section, (4) Jiujiang section, (5) Yueyang section, (6) Wuhan section, (7) Yichang section, (8) Chongqing section, and (9) Yibin section).

\subsection{Accuracy Evaluation of Downscaling Wind Speed}

We compared the similarity between $V_{\text {max_OBS }}$ and $V_{\text {max }} E R A$ or $V_{\text {max_WM }}$ by scatterplot, and analyzed the performance of $V_{\text {max_ERA }}$ and $V_{\text {max_WM }}$ by using the D statistic of the twosample Kolmogorov-Smirnov (K-S) test. This method is a non-parametric test based on the empirical cumulative distribution function (ECDF) and is used to assess the difference in ECDF between $\mathrm{N}$ data points $\left(Y_{1}, Y_{2}, \ldots, Y_{N}\right)$ in two datasets. First, the ECDF of $V_{\text {max_OBS }}-V_{\text {max }} E R A$ and $V_{\text {max_OBS }}-V_{\text {max_WM }}$ was calculated, then the ECDF was sorted in ascending order to obtain the absolute difference of the cumulative frequency series of the sample points. Finally, the D statistic of K-S was calculated for these sequences. The mean absolute error $(M A E)$ is the average of the absolute value of the error, and the coefficient of determination $\left(R^{2}\right)$ is the goodness fit between $V_{\text {max_OBS }}$ and $V_{\text {max_ERA }}$ or $V_{\text {max }}$ WM, respectively.

$$
Y_{N}=\frac{n_{i}}{N}
$$




$$
\begin{gathered}
D_{1}=Y_{i, \text { OBS }}-Y_{i, E R A} \\
D_{2}=Y_{i, \text { OBS }}-Y_{i, \mathrm{WM}} \\
M A E=\frac{1}{n} \sum_{i=1}^{n}\left|V_{i, \mathrm{OBS}}-V_{i, E R A / W M}\right| \\
R_{1,2}^{2}=1-\left(\frac{S S E_{\text {res } 1,2}}{S E_{\text {tot } 1,2}}\right) \\
S S E_{\text {res } 1,2}=\sum_{i=1}^{n}\left(V_{i, \mathrm{OBS}}-V_{i, E R A / W M}\right)^{2} \\
S E_{\text {tot } 1,2}=\sum_{i=1}^{n}\left(V_{i, \mathrm{OBS}}-\overline{V_{i, E R A / W M}}\right)^{2}
\end{gathered}
$$

where $Y_{N}$ is the ECDF value at point $N$, and $n_{i}$ is the number of points less than $Y_{i}$. ECDF is a step function that jumps up by $1 / n$ at each of the $n$ data points when there are repeated wind speed data. $Y_{i, W M}, Y_{i, E R A}$, and $Y_{i, O B S}$ are the ECDF values of $V_{\text {max } E R A}, V_{\text {max_WM }}$, and $V_{\text {max_OBS }}$ with $1 / n$ equal probability, respectively. $V_{i, E R A}, V_{i, W M}$, and $V_{i, O B S}$ are the maximum wind speed values for each station in the dataset, with smaller $M A E$ values indicating a good result as a difference between $V_{i, W M}$ and $V_{i, O B S}$ is smaller than the difference between $V_{i, E R A}$ and $V_{i, O B S}$. The increasing $R^{2}$ value indicates an improvement when comparing a regression of $V_{i, W M}$ and $V_{i, O B S}$ to a regression of $V_{i, E R A}$ and $V_{i, O B S}$.

\subsection{Nexus Analysis of Wind Speed and Land Use}

The area ratio of the downscaled maximum wind speed $A V_{i}(i=1, \ldots, 10)$ was classified by wind speed levels in the study area (Table 3$)$, and the area ratio of different land use types $\operatorname{ATC}_{j}(j=1, \ldots, 8)$ was obtained using land use data in the study area. Finally, the area ratio of wind speed $A_{k}$ per unit area for each land type was calculated after normalization (Equation (10)), where $k$ is the number of wind speed-land type classification units $(k=1$, ..., 80). The nexus analysis of wind speed and land use assesses the extent and impact of land use on wind speed and provided information for wind speed risk assessment.

$$
A_{k}=\frac{A V_{i} \cap A T C_{j}}{A T C_{j}}
$$

Table 3. Wind speed levels.

\begin{tabular}{cccc}
\hline No. & Wind Speed Level & Name & Threshold $\mathbf{( m / s )}$ \\
\hline 1 & 4 & Moderate breeze & $5.5-7.9$ \\
2 & 5 & Fresh breeze & $8.0-10.7$ \\
3 & 6 & Strong breeze & $10.8-13.8$ \\
4 & 7 & Moderate gale & $13.9-17.1$ \\
5 & 8 & Fresh gale & $17.2-20.7$ \\
6 & 9 & Strong gale & $20.8-24.4$ \\
7 & 10 & Whole gale & $24.5-28.4$ \\
8 & 11 & Storm & $28.5-32.6$ \\
9 & 12 & Typhoon & $32.6-37.0$ \\
10 & 13 & Hurricane & $\geq 37.0$ \\
\hline
\end{tabular}

\section{Results}

\subsection{Evaluation of Downscaling Effect of Maximum Wind Speed}

The downscaled annual maximum wind speed $\left(V_{\max \_W M}\right)$ was calculated using ERAInterim data and Equation (1) in the study area from 1980 to 2017, and it was used to evaluate the similarity of $V_{\text {max_OBS }}$ in comparison with $V_{\text {max }} E R A$ (Figure 4). The scatterplot of wind speed shows that the majority of the $V_{\text {max_OBS }}(7.58-15.44 \mathrm{~m} / \mathrm{s})$ and $V_{\text {max }} E R A$ $(2.76-7.88 \mathrm{~m} / \mathrm{s})$ comparisons are perpendicular to the $45^{\circ}$ line in the upstream area, with 
$V_{\text {max_ERA }}$ being underestimated compared with the observation value at most stations; the majority of the $V_{\text {max_OBS }}$ and $V_{\text {max_WM }}(7.1-13.12 \mathrm{~m} / \mathrm{s})$ comparisons are closer to the $45^{\circ}$ line with underestimation at a few stations. The majority of the $V_{\text {max_OBS }}(7.11-12.75 \mathrm{~m} / \mathrm{s})$ and $V_{\text {max } \_R A}(4.99-10.19 \mathrm{~m} / \mathrm{s})$ comparisons are closer to the $45^{\circ}$ line in the midstream area than the upstream area, and $V_{\text {max }} E R A$ values still show underestimations; the majority of the $V_{\text {max_OBS }}$ and $V_{\text {max_WM }}(6.22-10.83 \mathrm{~m} / \mathrm{s})$ comparisons are closer to the $45^{\circ}$ line with smaller underestimation. Difference in the regression line slope between $V_{\text {max_ERA }}(4.49-17.04 \mathrm{~m} / \mathrm{s})$ and $V_{\text {max_OBS }}(6.61-14.7 \mathrm{~m} / \mathrm{s})$ are at a greater angles to the $45^{\circ}$ line in the downstream area, and the $V_{\text {max } \_R A}$ values are higher than the $V_{\text {max }}$ OBS values at most stations; the linear regression line of $V_{\text {max_WM }}(5.9-17.55 \mathrm{~m} / \mathrm{s})$ and $V_{\text {max_OBS }}$ is close to the $45^{\circ}$ line, and only a few stations still have overestimations (e.g., $17.55 \mathrm{~m} / \mathrm{s}$ at Anqing station and $16.7 \mathrm{~m} / \mathrm{s}$ at Lushan station). The linear regression line of $V_{\max \_E R A}(2.76-17.04 \mathrm{~m} / \mathrm{s})$ and $V_{\text {max_OBS }}(6.61-15.44 \mathrm{~m} / \mathrm{s})$ is close to the $45^{\circ}$ line at major stations in the Yangtze River inland waterway, and the $V_{\text {max_OBS }}$ values are $>10 \mathrm{~m} / \mathrm{s}$, corresponding to $V_{\text {max } \_E R A}$ values of $<5 \mathrm{~m} / \mathrm{s}$ at most stations. The linear regression line of $V_{\max \_W M}(5.9-17.55 \mathrm{~m} / \mathrm{s})$ and $V_{\text {max_OBS }}$ has a small angle to the $45^{\circ}$ line, and $V_{\text {max_WM }}$ values are overestimated at a few stations. Figure 4 shows that the $V_{\text {max_WM }}$ values are closer to the $V_{\text {max_OBS }}$ values at most stations, with a good performance from 5 to $10 \mathrm{~m} / \mathrm{s}$, indicating that the accuracy of the downscaled data is significantly improved.
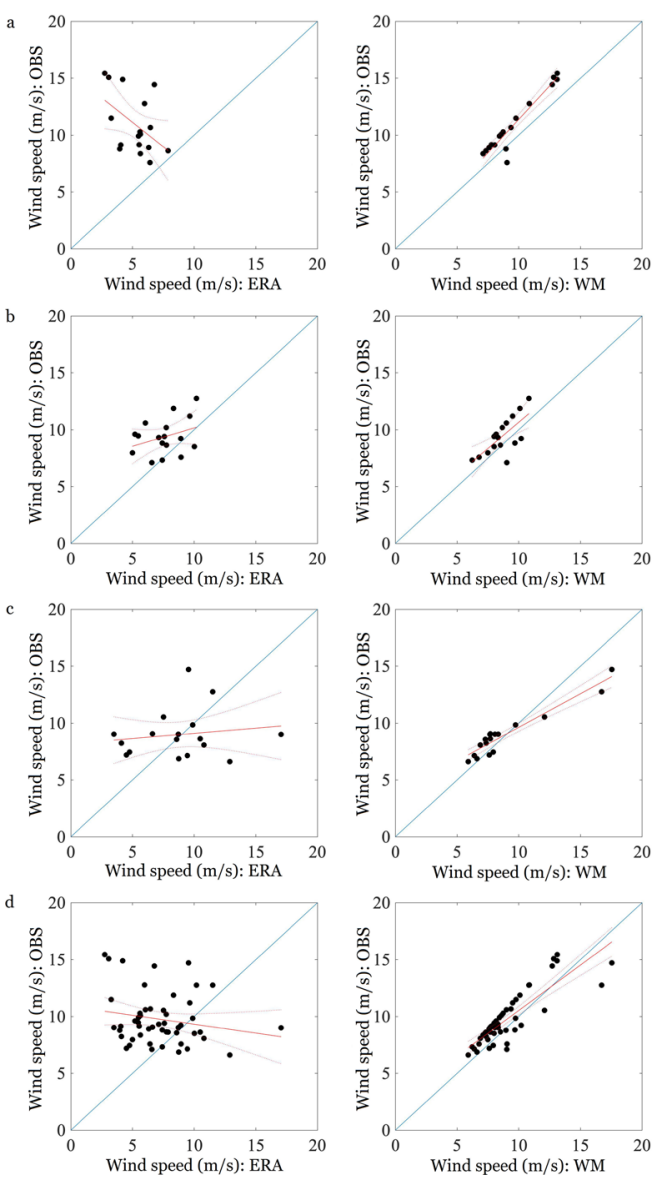

Figure 4. Scatterlplot comparisons for $V_{\max \_W M} V_{\text {max }} O B S$ and $V_{\max \_W M}-V_{\max \_E R A}$. (a) Upstream, (b) midstream, (c) downstream, and (d) Yangtze River inland waterway.

Boxplots of the three statistics show comparisons of maximum wind speed between $V_{\text {max_OBS }}$ and $V_{\text {max } E R A}$ and between $V_{\text {max_OBS }}$ and $V_{\text {max_WM }}$ (Figure 5): the downscaled D-statistic value decreases from 0.941 to 0.294 in the upstream, from 0.471 to 0.294 in the midstream, and from 0.235 to 0.412 in the downstream, indicating that the difference between the upstream and midstream samples is small and the performance is optimal in 
high-altitude upstream areas where the terrain is more complex; the difference between the downstream data increases and the effect is averaged. The D-statistic value of the Yangtze River inland waterway decreased from 0.49 to 0.27 , indicating that the accuracy of the downscaled product is generally better than that of $V_{\max \_E R A}$. The MAE value after downscaling decreased from 2.34 to 1.73 in the upstream, from 0.91 to 0.82 in the midstream, and from 1.34 to 1.00 in the downstream; the $M A E$ value of the Yangtze River inland waterway changed from 2.34 to 0.745 , although the change was not obvious in the downstream. The downscaled data scales tend to be concentrated, with only individual stations susceptible to extreme values. The downscaled $R^{2}$ values increased from 0.199 to 0.905 in the upper reaches, from 0.082 to 0.494 in the middle reaches, and from -0.009 to 0.898 in the lower reaches (the most significant increase); the overall $R^{2}$ value of the Yangtze River inland waterway changed from 0.026 to 0.72 , indicating a significant improvement in the goodness of fit of $V_{\text {max_WM }}$ after downscaling.
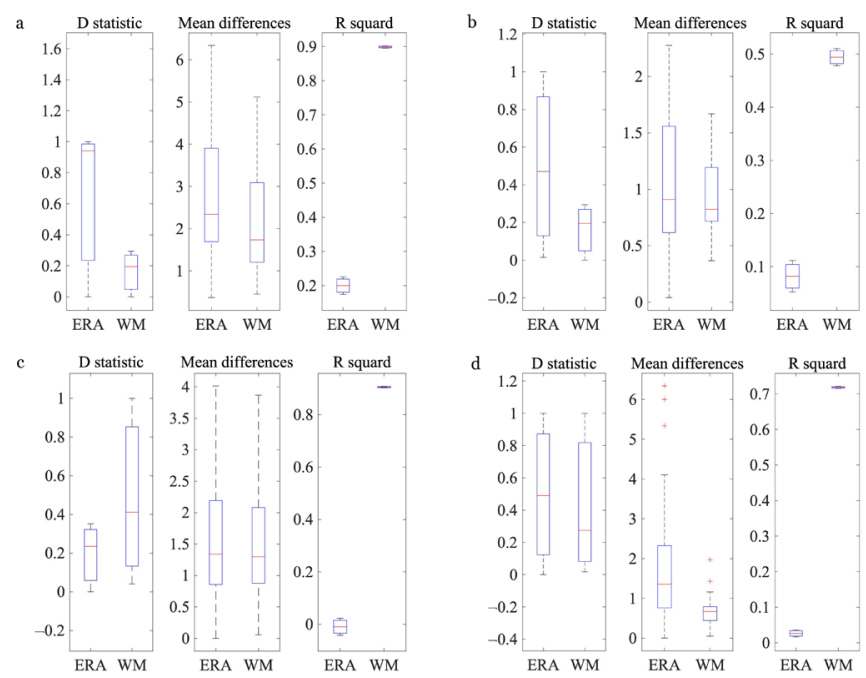

Figure 5. Boxplot comparison of D statistics of two-sample Kolmogorov-Smirnov test (left), mean absolute error (MAE; middle), and the coefficient of determination $\left(R^{2}\right.$; right) for $V_{\text {max_WM }} V_{\text {max_OBS }}$ and $V_{\text {max }} W M^{-} V_{\text {max }} E R A$. (a) Upstream, (b) midstream, (c) downstream, and (d) Yangtze River inland waterway.

The above statistical analysis shows that the upstream downscaled data have the smallest differences compared to the observed values and the best fit, but there are extreme values resulting in large differences and low concentration; the midstream downscaled data have small differences compared to the observed values and the highest concentration, but the fit is average; the downstream data have good concentration and fit, but the individual data are substantially different, resulting in lower sample quality. Despite the local variability and bias in the indicator analysis, the products obtained by the wind multiplier downscaling method are more suitable for characterizing the spatiotemporal variability of maximum wind speeds in the study area as compared with the ERA-Interim reanalysis data.

\subsection{Spatiotemporal Characteristics of Maximum Wind Speed}

The maximum wind speed values for the 14 stations in the Yangtze River channel, including $V_{\text {max_OBS }}, V_{\text {max }} E R A$, and $V_{\text {max_WM }}$, were extracted from downscaled wind-speed products. Temporal trend analysis shows (Figure 6) that $V_{\text {max_WM }}(10.01 \mathrm{~m} / \mathrm{s})$ is closer to the interannual mean value of $V_{\text {max_OBS }}(10.45 \mathrm{~m} / \mathrm{s})$ than $V_{\text {max_ERA }}(8.78 \mathrm{~m} / \mathrm{s})$ for the Yangtze River inland waterway; the interannual mean of $V_{\text {max_WM }}$ in the upper-middle section $(8.15-11.8 \mathrm{~m} / \mathrm{s})$ is also closer to the interannual mean of $V_{\text {max }}$ OBS $(8.58-11.64 \mathrm{~m} / \mathrm{s})$, while downstream the interannual means of $V_{\text {max_WM }}(10.74 \mathrm{~m} / \mathrm{s})$ and $V_{\text {max_OBS }}(11.34 \mathrm{~m} / \mathrm{s})$ are both lower than those of $V_{\text {max_ERA }}(12.24 \mathrm{~m} / \mathrm{s})$. 


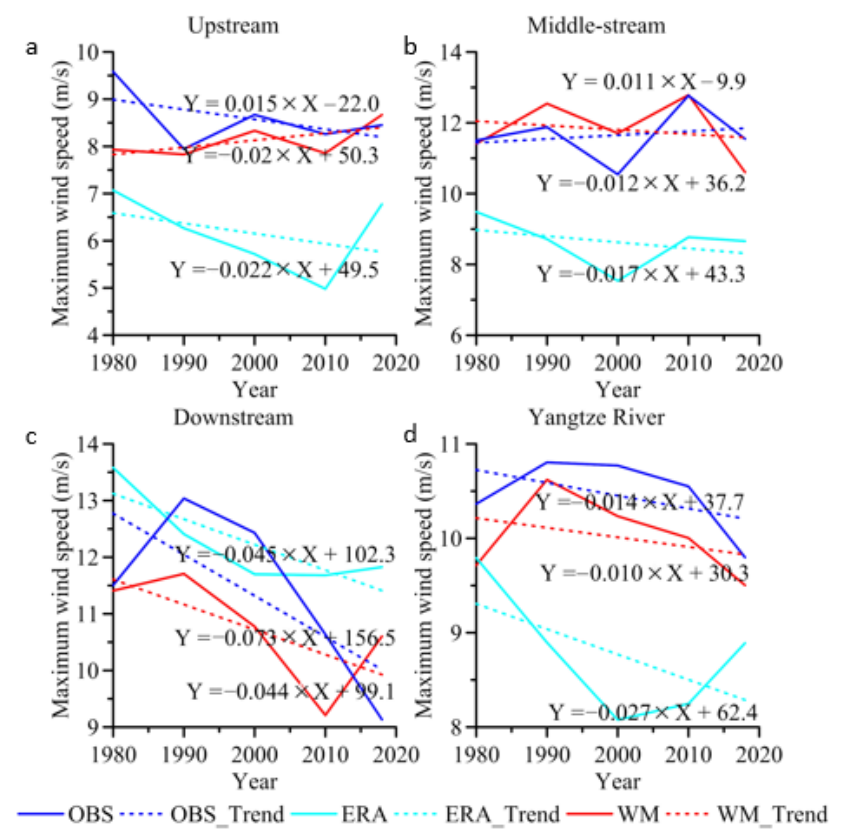

Figure 6. Interannual variation of $V_{\text {max }} O B S, V_{\text {max }} E R A$, and $V_{m a x}{ }_{-W M}$ of the Yangtze River inland waterway. (a) Upstream, (b) midstream, (c) downstream, and (d) Yangtze River inland waterway.

From the interannual variation tendency rate of the Yangtze River inland waterway, $V_{\text {max } \_W M}$ was $-0.1 \mathrm{~m} \cdot \mathrm{s}^{-1} \cdot 10 \mathrm{a}^{-1}, V_{\text {max }}$ OBS was $-0.14 \mathrm{~m} \cdot \mathrm{s}^{-1} \cdot 10 \mathrm{a}^{-1}$, and $V_{\text {max }} E R A$ was $-0.27 \mathrm{~m} \cdot \mathrm{s}^{-1} \cdot 10 \mathrm{a}^{-1}$, all with a weakly decreasing trend and three phases of significant change from 1980 to 2017: $V_{\text {max_WM }}\left(0.91 \mathrm{~m} \cdot \mathrm{s}^{-1} \cdot 10 \mathrm{a}^{-1}\right)$ and $V_{\text {max_OBS }}\left(0.44 \mathrm{~m} \cdot \mathrm{s}^{-1} \cdot 10 \mathrm{a}^{-1}\right)$ both showed an increasing trend, and $V_{\text {max } \_E R A}\left(-0.89 \mathrm{~m} \cdot \mathrm{s}^{-1} \cdot 10 \mathrm{a}^{-1}\right)$ showed a decreasing trend during 1980-1990; $V_{\max \_W M}\left(-0.30 \mathrm{~m} \cdot \mathrm{s}^{-1} \cdot 10 \mathrm{a}^{-1}\right), V_{\text {max_ERA }}\left(-0.32 \mathrm{~m} \cdot \mathrm{s}^{-1} \cdot 10 \mathrm{a}^{-1}\right)$, and $V_{\text {max }}$ OBS $\left(-0.13 \mathrm{~m} \cdot \mathrm{s}^{-1} \cdot 10 \mathrm{a}^{-1}\right)$ all showed a weakly decreasing trend during 1990-2010; subsequently $V_{\text {max_WM }}\left(-0.71 \mathrm{~m} \cdot \mathrm{s}^{-1} \cdot 10 \mathrm{a}^{-1}\right)$ and $V_{\text {max_OBS }}\left(-1.07 \mathrm{~m} \cdot \mathrm{s}^{-1} \cdot 10 \mathrm{a}^{-1}\right)$ showed a significant decrease and $V_{\text {max }} E R A\left(0.92 \mathrm{~m} \cdot \mathrm{s}^{-1} \cdot 10 \mathrm{a}^{-1}\right)$ showed an increasing trend. Overall, $V_{\text {max_WM }}$ was closer to the interannual variation pattern of $V_{\text {max_OBS }}$ than $V_{\text {max_ERA }}$. In terms of the upper-middle-downstream of the Yangtze River: $V_{\text {max }} W M$ had a weak upward trend $\left(0.15 \mathrm{~m} \cdot \mathrm{s}^{-1} \cdot 10 \mathrm{a}^{-1}\right)$, opposite to the trend to the $V_{\text {max_OBS }}\left(-0.2 \mathrm{~m} \cdot \mathrm{s}^{-1} \cdot 10 \mathrm{a}^{-1}\right)$ and $V_{\text {max } \_R A}\left(-0.22 \mathrm{~m} \cdot \mathrm{s}^{-1} \cdot 10 \mathrm{a}^{-1}\right)$ in the upstream; $V_{\max \_W M}\left(-0.12 \mathrm{~m} \cdot \mathrm{s}^{-1} \cdot 10 \mathrm{a}^{-1}\right)$ and $V_{\text {max } E R A}\left(-0.17 \mathrm{~m} \cdot \mathrm{s}^{-1} \cdot 10 \mathrm{a}^{-1}\right)$ both showed weak downward trends, slightly different from the weak upward trend of $V_{\max \_O B S}\left(0.11 \mathrm{~m} \cdot \mathrm{s}^{-1} \cdot 10 \mathrm{a}^{-1}\right)$ in the midstream; the interannual variabilities of $V_{\max } \mathrm{WM}_{-}, V_{\text {max }} \mathrm{OBS}$, and $V_{\max }$ ERA $\mathrm{all}$ showed weakly decreasing trends $\left(-0.44 \mathrm{~m} \cdot \mathrm{s}^{-1} \cdot 10 \mathrm{a}^{-1},-0.73 \mathrm{~m} \cdot \mathrm{s}^{-1} \cdot 10 \mathrm{a}^{-1}\right.$, and $-0.45 \mathrm{~m} \cdot \mathrm{s}^{-1} \cdot 10 \mathrm{a}^{-1}$, respectively) in the downstream. The difference in the tendency rate between the downscaled wind speed values and the observed values is less than $0.5 \mathrm{~m} \cdot \mathrm{s}^{-1} \cdot 10 \mathrm{a}^{-1}$, indicating that interannual variation in maximum wind speed along the Yangtze mainline and along different sections of the river is not significant.

The spatial distribution of $V_{\text {max_WM }}$ from 1980 to 2017 reflects the spatial characteristics of large nearshore, small inland, and undulating topographical areas (Figure 7). For example, the $V_{\text {max_WM }}$ values in the upstream Yibin-Chongqing section are clearly distributed in a continuous dense mountainous and hilly pattern $(14-37 \mathrm{~m} / \mathrm{s})$ with topographic variation, while the Yichang Three Gorges reservoir section is a low-value wind speed zone $(<10 \mathrm{~m} / \mathrm{s})$. The midstream Yueyang and Jiujiang sections both have high-value wind speed centers (11-20 m/s), and the Wuhan and Anqing sections show a sparse hill-like wind speed distribution pattern $(14-26 \mathrm{~m} / \mathrm{s})$. The downstream sections of Shanghai and Nanjing have a wide range of high-value wind speed zones $(11-20 \mathrm{~m} / \mathrm{s})$. In comparison with $V_{\text {max } E R A}, V_{\text {max_WM }}$ increased significantly after downscaling in the hilly sections (Yibin, Chongqing, Wuhan, and Anqing), with the range extending westward and showing wind 
speeds of $>37 \mathrm{~m} / \mathrm{s}$; the range of high-value centers narrows and decreases in the Yueyang and Jiujiang sections, and the range of high-value centers in the offshore sections (Nanjing and Shanghai) narrows toward the northeast.

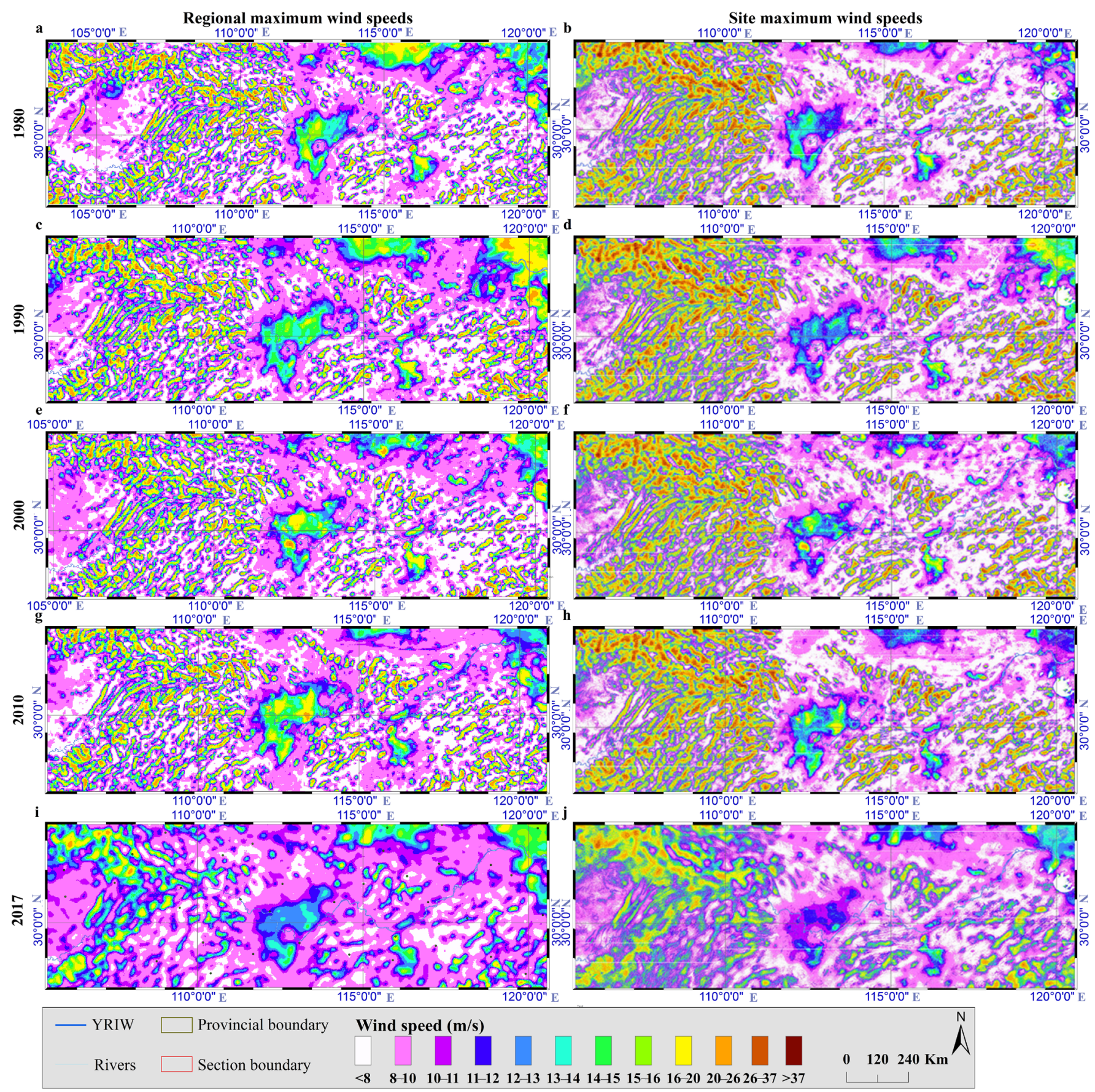

Figure 7. Spatial distribution comparison between $V_{\text {max } \_R A}$ and $V_{\text {max }} W M$ in the study area from 1980 to 2017. (a,b) 1980, (c,d) 1990, (e,f) 2000, (g,h) 2010, and (i,j) 2017.

The spatial distribution range of wind speeds on the Yangtze River inland waterway from 1980 to 1990 increased significantly, with $V_{\max -W M}$ reaching over $20 \mathrm{~m} / \mathrm{s}$ in the northeast direction in the Shanghai section and wind speed variation on a downscale significantly higher than the corresponding ERA-Interim data. The spatial maximum wind speed decreased by less than $16 \mathrm{~m} / \mathrm{s} \mathrm{m} / \mathrm{s}$ downstream of the Yangtze River inland 
waterway from 1990 to 2000, but the spatial variation was not significant in the midupper stream.

\subsection{Nexus Relationship between Downscaling Wind Speed and Land Use}

Changes in area by land use type were found (Figure 8): the proportion of cropland area has been decreasing year by year, accelerating from $43.39 \%$ before 2010 to $33.28 \%$ in 2017 , a significant decrease of $\sim 10.11 \%$ in 8 years. Forestland increased steadily from $31.86 \%$ in 1980 to $33.28 \%$ in 2017; the proportions of grassland, shrubland, wetland, and water area remained largely unchanged. The proportion of impervious surfaces has increased annually from 1980 and accelerated after 2010, from $2.75 \%$ in 1980 to $12.18 \%$ in 2017, an increase of approximately $9.43 \%$, indicating continued urbanization and an accelerating trend in recent years. The proportion of tundra and snow area is approximately 0 , but a very small amount of glacier is present in the study area, and its effect on local wind speed variation remains to be studied.

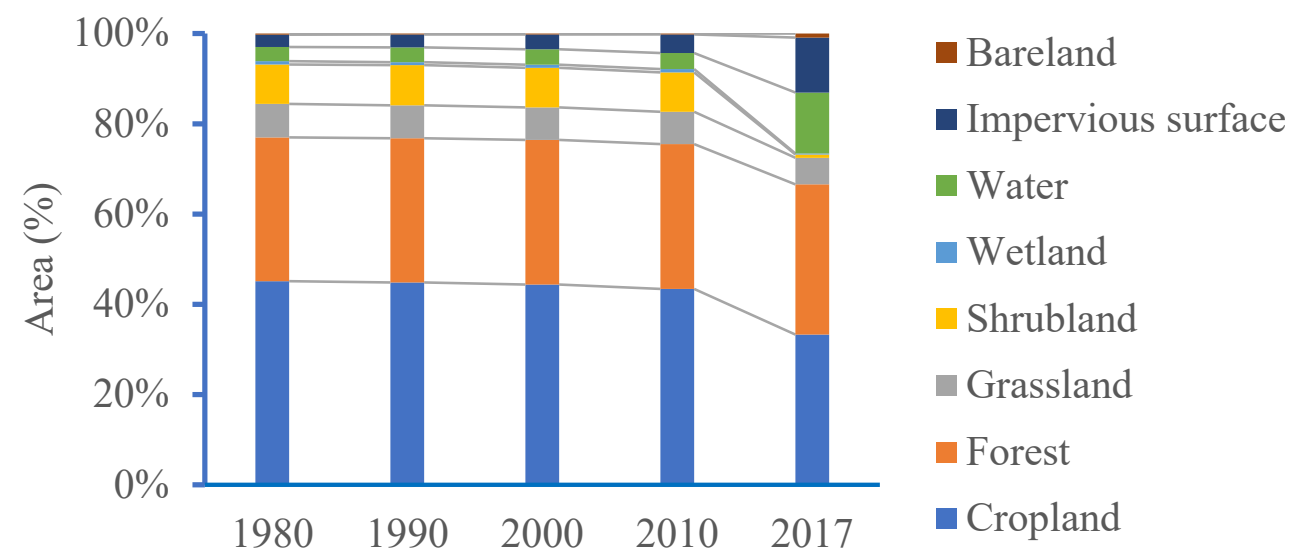

Figure 8. Percentage changes in land use area in the study area from 1980 to 2017.

Nexus relationship analysis shows (Figure 9) that arable $A_{k}$ values increase with wind speed and then decrease; the proportion of grade 4 wind speed is $0.18-0.28$, the proportion of grade 5 wind speed is the largest $(0.36-0.52)$, the proportion of grade 6 wind speed is $0.21-0.24$, the proportion of grade 7 wind speed is $0.04-0.11$, the proportion of grade 8 wind speed is $0.01-0.04$, the proportion of grade 9 wind speed is $0-0.02$. Wind speed of grade 10 or above accounts for $0.02-0.24$, grade 7 for $0.04-0.11$, grade 8 for $0.01-0.04$, grade 9 for $0-0.02$, and grade 10 or above for $<0.02$. The rate of change for 2010-2017 was significantly higher than that for 1980-2010; for example, the wind speed of grade 4 accelerated from 0.29 to 0.18 , the wind speed of grade 5 accelerated from 0.37 to 0.52 , the wind speed of grade 6 increased from 0.21 to 0.24 , and the wind speed of grade 7 and above decreased year by year. The pattern of change for forestland is similar to that of cropland, with the proportion of grade 4 wind speeds ranging from 0.13 to 0.22 , grade 5 wind speed ranging from 0.22 to 0.30 , and grade 6 wind speed ranging from 0.18 to 0.31 . From 2010 to 2017 grade 6 wind speed accelerated down from 0.20 to 0.13 , grade 5 wind speed accelerated up from 0.23 to 0.30 , and grade 6 wind speed accelerated down from 0.19 to 0.31 ; the proportion of grade 5-7 wind speed increased year by year, of which the proportion of grade 6-7 wind speed increased significantly. The proportion of wind speeds for the remaining land use types (especially above grade 8) declined significantly from 2010 to 2017, even reaching a value of 0 . The proportion of grade 7 wind speed and above for grassland, shrubland, and wetland was higher than that for cropland and woodland, and the proportion of grade 5-7 wind speed increased slightly, while the proportion of wind speed in the remaining types (especially gale force 9 and above) decreased significantly, or even to 0 . The proportion of grade 4-6 wind speed in the bare land decreased year by year, but the proportion of grade 7-10 wind speed increased more significantly, by approximately one order of magnitude. The proportion of wind speed above grade 11 decreased significantly, even 
to 0 , indicating that the areas where these land types exist are prone to gale force weather. The proportion of grade 4-8 wind speed in water areas was the opposite of and does not change significantly from land, with the remaining classes increasing slightly, especially the proportion of grade 9-10 wind speeds appearing from 0 to 0.01 from 2010 to 2017 . The proportion of force 4-5 gales increased on construction land and decreased for the remaining types, while the proportion of force 8 gales and above declined significantly.
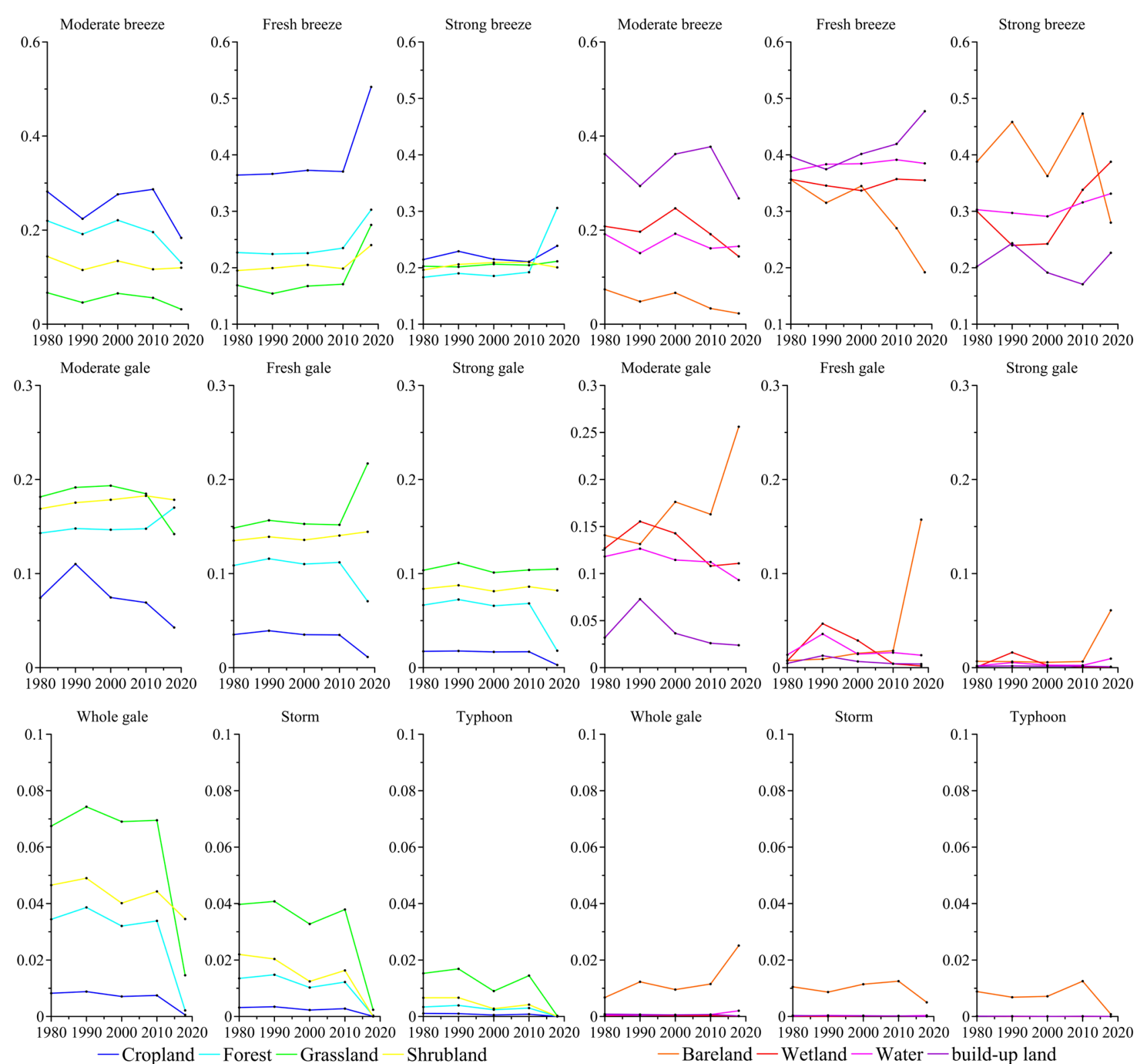

Figure 9. Relationship between land use and $V_{m a x \_W M}$ in the Yangtze River inland waterway from 1980 to 2017.

\section{Discussion}

\subsection{Main Findings}

Large-scale spatiotemporal variations in wind speed are perturbed by hourly and spatial-scale wind events in different underlayers, and there are pronounced regional differences in economic development and urbanization in the areas surrounding the Yangtze River inland waterway. For example, the rapid socio-economic development of the middownstream of the Yangtze River inland waterway and offshore areas can increase the uncertainty of wind speed frequency changes. We also found a significant underestimation of wind speeds in upstream areas in the reanalysis data, which may be a reflection of 
errors in the reanalysis data assimilation system itself. For example, the model may not correctly describe local topography, climate, and surface parameters; in addition, there may be missing meteorological data and low-resolution input data. The reanalysis data represent large-scale climate changes caused by atmospheric circulation, greenhouse gases, etc. However, this is not sensitive to changes in land use type, and the results of this study confirm this limitation. However, ERA-Interim reanalysis data can be significantly improved by the wind multiplier downscaling method, and this more accurate wind speed data can be used for refined analysis of the maximum wind speed characteristics of the waterway. The wind multiplier downscaling method better integrates the combined effects of land use and topography on wind speed, and the evaluation of statistical indicators shows that the downscaling products have significantly improved accuracy and can more accurately reflect the spatial and temporal distribution characteristics of maximum wind speed in the study area.

Land use has a greater impact on overland winds than overwater winds in the study area. The maximum wind speed measured by the weather stations tends to decrease with increasing roughness of the subsurface owing to the increase in the number of buildings along with accelerated urbanization; the roughness of the water is smaller and the increase in the number of buildings around river banks and seawalls tends to form a river valley effect, resulting in a continuous decrease in the wind speed difference between water and land. Correlation analysis between land use and maximum wind speed shows that, except for bare land, the proportions of wind speed over the different land types increase and then decrease with rising wind speed, especially for grade 9 wind speed or above; the proportion was smallest in 2017. Bare land shows a trend of increasing wind speed in grade 9-10 wind speed, while the proportion of wind speed over water grade 4-8 is the opposite of that on land. The proportion is opposite to that of land, with no significant change in trend, and the rest of the classes are slightly increased, especially grade 9-10, which showed an increasing trend from 2010 to 2017. This study also demonstrates that although the risk of strong winds over water has weakened, the risk of extreme wind speeds has increased, and so the risk of damage to navigation and the region from extreme wind speeds along the Yangtze River inland waterway under climate change continues to increase.

\subsection{Limitations of Study Approach}

Anthropogenic activity substantially affects surface roughness, which has become a major cause of variation in the maximum wind speed in the study area. However, there are uncertainties in the analysis of the effects of land use on the maximum wind speed. For example, land use can lead to an increase in canopy resistance, which has a blocking effect on surface maximum wind speed and can change the thermodynamic properties of the surface, which in turn causes changes in surface maximum wind speed by altering local circulation and turbulent fluxes. Moreover, there is a lack of reliable data methods and assessment techniques, and the development of relevant models should be enhanced. Many stations in the Yangtze River inland waterway area are located within the transition zone between urban and suburban areas, and urban expansion not only increases surface roughness, but also leads to heat island circulation and turbulent flux perturbations, which have an important impact on the monitoring results of local wind fields.

When analyzing the impact of land use on the maximum surface wind speed based on station observations, the above thermodynamic effects should be taken into account, and existing reanalysis data should be corrected for cross-scale thermodynamic information to improve the accuracy of the observations. Moreover, the spatiotemporal resolution of wind speed products should be further strengthened, and higher resolution wind speed downscaling techniques should be developed through integration with high precision and long time series of geographical elements (e.g., land use, impermeable layer). Finally, wind speed event changes are significantly influenced by climate change, and wind speed change predictions under different climate change scenarios should be further developed 
to obtain more complete spatiotemporal characteristics of wind speed and its potential change trends in the study area.

\section{Conclusions}

This study proposes an integrated analysis method for wind multiplier downscaling and accuracy assessment, and a comprehensive assessment of the acquired downscaled maximum wind speed spatiotemporal characteristics. The modeling approach is generally applicable to the study area, with good accuracy and spatiotemporal representation of downscaled products, and the main conclusions obtained are as follows. (1) The trends of the site downscaled $V_{\text {max_WM }}(5.9-17.55 \mathrm{~m} / \mathrm{s})$ and observed $V_{\text {max_OBS }}(6.61-15.44 \mathrm{~m} / \mathrm{s})$ are better fitted (especially $5-10 \mathrm{~m} / \mathrm{s}$ ), and the downscaled accuracy is significantly improved; the upstream statistic $\mathrm{D}$ drops from 0.941 to 0.294 and $R^{2}$ rises to 0.905 , but there are extreme values leading to large differences in maximum wind speed and low concentration (MAE decreasing from 2.34 to 1.73 ); midstream $D$ drops from 0.471 to 0.294 and has the highest concentration (MAE decreasing from 0.91 to 0.82$)$, but the fit is average $\left(R^{2}\right.$ rises to 0.494$)$; downstream data concentration (MAE decreasing to 1 ) and fit ( $R^{2}$ from -0.009 to 0.898 ) are better, but individual data are too different resulting in lower sample quality ( $\mathrm{D}$ increasing to 0.412 ). (2) Downscaled products and interannual rates of variability at the stations ( -0.01 and $-0.014 \mathrm{~m} \cdot \mathrm{s}^{-1} \cdot 10 \mathrm{a}^{-1}$ ) are much closer, with both showing increasing trends from 1980 to $1990\left(0.91\right.$ and $\left.0.44 \mathrm{~m} \cdot \mathrm{s}^{-1} \cdot 10 \mathrm{a}^{-1}\right)$, weakening by $2010\left(-0.30\right.$ and $\left.-0.13 \mathrm{~m} \cdot \mathrm{s}^{-1} \cdot 10 \mathrm{a}^{-1}\right)$, followed by significant decreases $\left(-0.71\right.$ and $\left.-1.07 \mathrm{~m} \cdot \mathrm{s}^{-1} \cdot 10 \mathrm{a}^{-1}\right)$. Wind speeds at both midand down-stream stations increased significantly from 1980 to 1990 and decreased significantly from 2010 to 2017. (3) $V_{\text {max_WM }}$ shows spatial characteristics of large nearshore wind speed $(14-37 \mathrm{~m} / \mathrm{s})$, small inland wind speed $(11-20 \mathrm{~m} / \mathrm{s})$, and wind speed over undulating topography. The $V_{\max \_W M}$ value in the hilly terrain section (Yibin and Chongqing) increases significantly and expands westward, the center of high-value region of the Yueyang and Jiujiang section narrows and decreases, and the center of the high-value region in the Nanjing and Shanghai section narrows to the northeast. The spatial distribution range of wind speed increased from 1980 to 1990, with $V_{\text {max_WM }}$ values reaching $>20 \mathrm{~m} / \mathrm{s}$ in the Shanghai section. The maximum wind speed in the downstream region decreased below $16 \mathrm{~m} / \mathrm{s}$ from 1990 to 2000, with insignificant changes in the middle and upstream regions from 2000 to 2010. The overall changes were insignificant from 2010 to 2017. The most significant differences were found in the upstream region in 2017, with $V_{\text {max_WM }}$ values reaching $20 \mathrm{~m} / \mathrm{s}$ or more, and a significant decrease in the mid and downstream regions. This suggests that the wind multiplier downscaling method effectively integrates the effects of surface processes on wind speed, which is missing in the reanalysis data, resulting in better interannual variability characteristics.

Research on extreme weather and climate events such as maximum wind speed can improve disaster prevention and management, and the design of shipping on the Yangtze River inland waterway. For the navigable environment of the Yangtze River inland waterway, the basin environment is complex, and the Yangtze River crosses three major geomorphic terrains with large topographic drop-offs and significant differences in climatic and meteorological conditions, with an increasing trend in the frequency of extreme events $[37,38]$. The natural rate of climate variability in the monsoon region has a significant impact on the Yangtze River inland waterway, such as the large-scale atmospheric circulation changes caused by the East Asian monsoon fluctuations, The El Niño-Southern Oscillation (ENSO) and the Pacific Ocean interdecadal oscillation [39]. It is worth noting that the wind speed changes in the Yangtze River may be a sensitive indicator of global climate change. It should also be noted that the Yangtze River inland waterway is highly exposed and vulnerable and is also affected by transport policy, and socio-economic and technological developments. Our study provides valuable data and knowledge support for navigational risk management, identification of local areas at high wind speed risk, and wind emergency management in the Yangtze River. Research on the trends of extreme weather events on the Yangtze River inland waterway under the 
combined influence of climate change and human activities should be strengthened in the future, and high-precision regional model data and spatial analysis methods should be used to clarify the different influencing factors of disaster-causing risks in each section of Yangtze River inland waterway.

Author Contributions: Conceptualization, L.L. and F.Z. Formal analysis, L.L. Methodology, L.L. Software, L.L. Supervision, F.Z. Validation, L.L. and F.Z. Writing-original draft, L.L. Writingreview and editing, L.L. and F.Z. All authors have read and agreed to the published version of the manuscript.

Funding: This research was supported by the National Natural Science Foundation of China (grant nos. 51709218).

Acknowledgments: The dataset of land use maps from 1980 to 2010 was provided by the National Tibetan Plateau Data Center (http:/ / data.tpdc.ac.cn, accessed on 13 September 2021).

Conflicts of Interest: The authors declare no conflict of interest.

\section{References}

1. IPCC. Climate Change 2021: The Physical Science Basis, Contribution of Working Group I to the Sixth Assessment Report of the Intergovernmental Panel on Climate Change; Masson-Delmotte, V., Zhai, A.P., Pirani, S.L., Connors, C., Péan, S., Berger, N., Caud, Y., Chen, L., Goldfarb, M.I., Gomis, M., et al., Eds.; Cambridge University Press: Cambridge, UK, 2021.

2. Gomez, F.J.; Ávila, H.; Gutierrez, R.R. Hydrometeorological Data-Based Methodology for Navigability Risk Analysis at Waterways: Case Study for Magdalena River. J. Waterw. Port Coast. Ocean Eng. 2021, 147, 05021011. [CrossRef]

3. Lung, T.; Lavalle, C.; Hiederer, R.; Dosio, A.; Bouwer, L.M. A multi-hazard regional level impact assessment for Europe combining indicators of climatic and non-climatic change. Glob. Environ. Chang. 2013, 23, 522-536. [CrossRef]

4. Suo, X.; Fu, G.; Wang, C.; Jia, Q. An Application of 24Model to Analyse Capsizing of the Eastern Star Ferry. Pol. Marit. Res. 2017, 24, 116-122. [CrossRef]

5. Zhang, R.; Zhang, S.; Luo, J.; Han, Y.; Zhang, J. Analysis of near-surface wind speed change in China during 1958-2015. Theor. Appl. Clim. 2019, 137, 2785-2801. [CrossRef]

6. Li, Y.; Chen, Y.; Li, Z. Effects of land use and cover change on surface wind speed in China. J. Arid Land 2019, 11, 345-356. [CrossRef]

7. Lu, Y.; Wu, B.; Yan, N.; Zhu, W.; Zeng, H.; Ma, Z.; Xu, J.; Wu, X.; Pang, B. Quantifying the Contributions of Environmental Factors to Wind Characteristics over 2000-2019 in China. ISPRS Int. J. Geo-Inf. 2021, 10, 515. [CrossRef]

8. Zeng, Z.; Ziegler, A.D.; Searchinger, T.; Yang, L.; Chen, A.; Ju, K.; Piao, S.; Li, L.Z.X.; Ciais, P.; Chen, D.; et al. A reversal in global terrestrial stilling and its implications for wind energy production. Nat. Clim. Chang. 2019, 9, 979-985. [CrossRef]

9. Kalnay, E.; Cai, M. Impact of urbanization and land-use change on climate. Nature 2003, 423, 528-531. [CrossRef]

10. Zhou, L.; Dickinson, R.E.; Tian, Y.; Fang, J.; Li, Q.; Kaufmann, R.K.; Tucker, C.J.; Myneni, R. Evidence for a significant urbanization effect on climate in China. Proc. Natl. Acad. Sci. USA 2004, 101, 9540-9544. [CrossRef]

11. Li, Z.; Yan, Z.; Tu, K.; Liu, W.; Wang, Y. Changes in wind speed and extremes in Beijing during 1960-2008 based on homogenized observations. Adv. Atmos. Sci. 2011, 28, 408-420. [CrossRef]

12. Aboshosha, H.; El Damatty, A. Engineering method for estimating the reactions of transmission line conductors under downburst winds. Eng. Struct. 2015, 99, 272-284. [CrossRef]

13. Kislov, A.; Matveeva, T. Extreme Values of Wind Speed over the Kara Sea Based on the ERA5 Dataset. Atmos. Clim. Sci. 2021, 11, 98-113. [CrossRef]

14. Searchinger, T.; Wirsenius, S.; Beringer, T.; Dumas, P. Assessing the efficiency of changes in land use for mitigating climate change. Nature 2018, 564, 249-253. [CrossRef]

15. Boé, J.; Terray, L.; Habets, F.; Martin, E. Statistical and dynamical downscaling of the Seine basin climate for hydro-meteorological studies. Int. J. Clim. 2007, 27, 1643-1655. [CrossRef]

16. Guo, Q.; Huang, R.; Zhuang, L.; Zhang, K.; Huang, J. Assessment of China's Offshore Wind Resources Based on the Integration of Multiple Satellite Data and Meteorological Data. Remote Sens. 2019, 11, 2680. [CrossRef]

17. Lee, C.-Y.; Camargo, S.; Sobel, A.H.; Tippett, M.K. Statistical-Dynamical Downscaling Projections of Tropical Cyclone Activity in a Warming Climate: Two Diverging Genesis Scenarios. J. Clim. 2020, 33, 4815-4834. [CrossRef]

18. Koşar, O.; Özgür, M.A. Wind energy resource assessment of Kütahya, Turkey using WAsP and layout optimization. Proc. Inst. Mech. Eng. Part A J. Power Energy 2021, 235, 629-640. [CrossRef]

19. Vandal, T.; Kodra, E.; Ganguly, A.R. Intercomparison of machine learning methods for statistical downscaling: The case of daily and extreme precipitation. Theor. Appl. Clim. 2018, 137, 557-570. [CrossRef]

20. Chandrasekar, R.; Balaji, C. Impact of physics parameterization and 3DVAR data assimilation on prediction of tropical cyclones in the Bay of Bengal region. Nat. Hazards 2016, 80, 223-247. [CrossRef] 
21. Kumari, K.V.; Sagar, S.K.; Viswanadhapalli, Y.; Dasari, H.P.; Rao, S.V.B. Role of Planetary Boundary Layer Processes in the Simulation of Tropical Cyclones Over the Bay of Bengal. Pure Appl. Geophys. PAGEOPH 2018, 176, 951-977. [CrossRef]

22. Xu, Z.; Han, Y.; Yang, Z. Dynamical downscaling of regional climate: A review of methods and limitations. Sci. China Earth Sci. 2018, 62, 365-375. [CrossRef]

23. Montero, G.; Rodríguez, E.; Oliver, A.; Calvo, J.; Escobar, J.M.; Montenegro, R. Optimisation technique for improving wind downscaling results by estimating roughness parameters. J. Wind. Eng. Ind. Aerodyn. 2018, 174, 411-423. [CrossRef]

24. Lim, Y.; Cai, M.; Kalnay, E.; Zhou, L. Observational evidence of sensitivity of surface climate changes to land types and urbanization. Geophys. Res. Lett. 2005, 32. [CrossRef]

25. Laapas, M.; Lehtonen, I.; Venäläinen, A.; Peltola, H.M. The 10-Year Return Levels of Maximum Wind Speeds under Frozen and Unfrozen Soil Forest Conditions in Finland. Climate 2019, 7, 62. [CrossRef]

26. Venäläinen, A.; Laapas, M.; Pirinen, P.; Horttanainen, M.; Hyvönen, R.; Lehtonen, I.; Junila, P.; Hou, M.; Peltola, H.M. Estimation of the high-spatial-resolution variability in extreme wind speeds for forestry applications. Earth Syst. Dyn. 2017, 8, 529-545. [CrossRef]

27. Yang, Y.; Zhang, M.; Liu, W.; Wang, J.; Li, X. Relationship between Waterway Depth and Low-Flow Water Levels in Reaches below the Three Gorges Dam. J. Waterw. Port Coast. Ocean Eng. 2019, 145, 04018032. [CrossRef]

28. Simmons, A.; Willett, K.; Jones, P.; Thorne, P.; Dee, P. Low-frequency variations in surface atmospheric humidity, temperature, and precipitation: Inferences from reanalyses and monthly gridded observational data sets. J. Geophys. Res. 2010, 115. [CrossRef]

29. Zhou, C.; Wang, K. Contrasting daytime and nighttime precipitation variability between observations and eight reanalysis products from 1979 to 2014 in China. J. Clim. 2017, 30, 6443-6464. [CrossRef]

30. Chinese Academy of Sciences Resource and Environmental Science Data Center. Landuse Dataset in China (1980-2015); National Tibetan Plateau Data Center: Beijing, China, 2019; Available online: http:/ / www.resdc.cn/ (accessed on 13 September 2021).

31. Gong, P.; Liu, H.; Zhang, M.; Li, C.; Wang, J.; Huang, H.; Clinton, N.; Ji, L.; Li, W.; Bai, Y.; et al. Stable classification with limited sample: Transferring a 30-m resolution sample set collected in 2015 to mapping 10-m resolution global land cover in 2017. Sci. Bull. 2019, 64, 370-373. [CrossRef]

32. Jarvis, A.; Reuter, A.; Nelson, E. Guevara, Hole-Filled SRTM for the Globe Version 4. CGIAR-CSI SRTM 90m Database. 2008. Available online: http:/ / srtm.csi.cgiar.org (accessed on 13 September 2021).

33. Liu, L.; Liang, Y.; Hashimoto, S. Integrated assessment of land-use/coverage changes and their impacts on ecosystem services in Gansu Province, northwest China: Implications for sustainable development goals. Sustain. Sci. 2019, 15, 297-314. [CrossRef]

34. Standards Australia International Ltd. and Standards New Zealand. AS/NZS 1170.2-Australia/New Zealand Standard Structural Design Actions (Part 2. Wind Actions); Standards Australia: Sydney, Australia, 2011.

35. Lin, X.; Nadimpalli, K. Computational Methods for Estimating Wind Local Effects as Part of Wind Risk Assessment. In Proceedings of the 6th Pacific Conference on Wind Engineering, Seoul, Korea, 12-14 September 2005.

36. Nikkho, S.K.; Heidarinejad, M.; Liu, J.; Srebric, J. Quantifying the impact of urban wind sheltering on the building energy consumption. Appl. Therm. Eng. 2017, 116, 850-865. [CrossRef]

37. Guan, Y.; Zhang, J.; Zheng, F.; Wang, B. Trends and variability of daily temperature extremes during 1960-2012 in the Yangtze River Basin, China. Glob. Planet. Chang. 2015, 124, 79-94. [CrossRef]

38. Guan, Y.; Zheng, F.; Zhang, J.; Wang, B. Trends and variability of daily precipitation and extremes during 1960-2012 in the Yangtze River Basin, China. Int. J. Clim. 2016, 37, 1282-1298. [CrossRef]

39. Risbey, J.; Lewandowsky, S.; Langlais, C.; Monselesan, D.; O'Kane, T.; Oreskes, N. Well-estimated global surface warming in climate projections selected for ENSO phase. Nat. Clim. Chang. 2014, 4, 835-840. [CrossRef] 